\title{
Identification of Mechanism and Pathway of the Interaction between the African Traditional Medicine, Sutherlandia Frutescens, and the Antiretroviral Protease Inhibitor, Atazanavir, in Human Subjects Using Population Pharmacokinetic (PK) Analysis.
}

\author{
A.C. Müller ${ }^{1}$, M. P. Ducharme ${ }^{2}$ and I.Kanfer ${ }^{1}$ \\ ${ }^{1}$ Faculty of Pharmacy, Rhodes University, Grahamstown, South Africa, ${ }^{2}$ Learn and Confirm Inc. St-Laurent Qc., Canada. \\ Received, July25, 2018; Accepted, August 27, 2018; Published, August 27, 2018.
}

\section{INTRODUCTION}

African traditional medicines (ATMs) are commonly used by HIV/AIDS patients in South Africa [1-4]. The use of the indigenous Southern African plants, Hypoxis hemerocallidea (African potato) and Sutherlandia frutescens (SF) for the treatment of HIV/AIDS has previously been described. [5]. The risk which such ATMs may pose to the safety and efficacy of antiretrovirals (ARVs) and the potential mechanisms which underlie such effects may have clinical significance and relevance and yet there is a dearth of knowledge in this regard.

The protease inhibitor (PI), atazanavir (ATV), like other PIs, is a substrate of the efflux transporter, P-gp [6,7], which modulates absorption in the small intestine, as well as CYP3A4 and CYP3A5 [8] enzymes which facilitate metabolism in the small intestine and liver. ATV may thus be susceptible to pharmacokinetic (PK) interactions with agents able to modulate the activities of this transporter and family of CYP enzymes, thereby potentially altering the safety or therapeutic profile of the PI.

We conducted in vitro studies [9] which showed that aqueous extracts $(10 \mathrm{mg} / \mathrm{ml})$ of SF may have the potential to reduce ATV absorption and to inhibit ATV metabolism. A methanolic extract of SF in which less polar constituents in comparison to the aqueous extract are likely present, may also inhibit ATV metabolism. Triterpenoid and flavonoid glycosides as well as D-Pinitol and L-Canavanine are known to be present in SF [10-13]. A triterpenoid glycoside fraction isolated from SF enhanced absorption and metabolism of ATV. These results alluded to the potential for SF to induce a drug-drug interaction with ATV. Furthermore, synergistic and contradictory effects were observed for different extracts and components of the plant and it was not clear which of these would predominate. An in vivo study with a PK analysis was required to provide further insight into a drug-drug interaction, if any.

The rate and extent to which a drug reaches the systemic circulation, may be used as a predictor of a clinical response which may lead to the therapeutic and/or toxic effects of a drug. Changes in the bioavailability of a drug in an individual as a result of an interaction with another drug, food or herbal medicine may thus alter these pharmacodynamic (PD) responses, thereby impacting on the efficacy or toxicity of the prescribed medication [14-16].

Clinical drug-drug interaction studies are designed to compare substrate (S) drug concentrations with and without an interacting (I) drug in humans [14-16]. The most commonly used PK parameters of the substrate drug in the analysis of PK oral drug-drug interaction data include the area under the plasma concentration vs time curve (AUC), the peak plasma concentration $\left(\mathrm{C}_{\max }\right)$, the time to reach $\mathrm{C}_{\max }\left(\mathrm{t}_{\max }\right)$, and the minimum concentration $\left(\mathrm{C}_{\min }\right)$.

An analogy may be drawn between drug-drug interaction and bioequivalence studies in that both seek to ascertain whether a clinically significant change in bioavailability of a drug has occurred when administered under different conditions [1417], where such conditions are either the coadministration of another drug (drug-drug interactions) or the delivery of the same drug in a different formulation (bioequivalence) [17]. The European [14], US [15] and Canadian [16] drug-drug interaction guidances therefore all recommend that the statistical approach for bioequivalence be applied

Corresponding Author: Dr. I. Kanfer, Leslie Dan Faculty of Pharmacy, University of Toronto, Toronto, ON, Canada, E-mail: izzy.kanfer@utoronto.ca 
to drug-drug interaction studies. The underlying principle is always that for given lower and upper tolerance limits, bioequivalence (or no drug-drug interaction) is claimed if the difference between the mean (or ratio of geometric mean) of the test and reference (or S and S + I) of a PK parameter is within the tolerance limits with some degree of certainty [18]. In a drug-drug interaction study, if both CI limits fall inside the no-effect boundary of $0.8-1.25$, then no clinically significant interaction is implied.

An ATV single dose/ SF multiple doses, one sequence crossover drug-drug interaction study in healthy male subjects was conducted [19] and revealed that the lower limit of a $90 \% \mathrm{CI}$ interval for the geometric mean ratios (ATV/ATV $+\mathrm{SF}$ ) of both $\mathrm{C}_{\max }$ and $\mathrm{AUC}_{0-24 \mathrm{hr}}$ were below the "no-effect" boundary of $0.8-1.25$. This implied that SF reduced the systemic exposure of ATV, which may have clinical significance, with respect to the safety and/or efficacy of ATV.

When a drug-drug interaction occurs, changes in PK exposure parameters such as $\mathrm{C}_{\max }$ and AUC may not provide complete information regarding the particular mechanism of interaction. For example, changes in these exposure metrics could be due to changes in absorption or in the clearance or elimination of the drug itself, or both. In the aforementioned study [19], a visual comparison of the concentration-time profiles of ATV (i) in the absence and presence (ii) of SF showed a similar rate of elimination, suggesting that the mechanism by which SF reduced the systemic exposure of ATV may have been more likely related to absorption rather than elimination (Figure 1)[19]. Fitting the ATV and ATV + SF drug-drug interaction data with a robust population pharmacokinetic model may thus be helpful in confirming or refuting the postulation(s) of the possible mechanism(s) of the interaction [20-22].

The main objective of this study was to use a population PK analysis to fit and explain the plasma concentration vs. time profiles of ATV [19], in order to understand and postulate on the potential mechanism(s) of the drug-drug interaction.

\section{Study Population and Study Design}

The methods, materials and study population were as previously described [19,23]. The study design involved a one-sequence crossover, two phase clinical study with a single dose/multiple dose regimen combination for ATV and SF respectively [19].

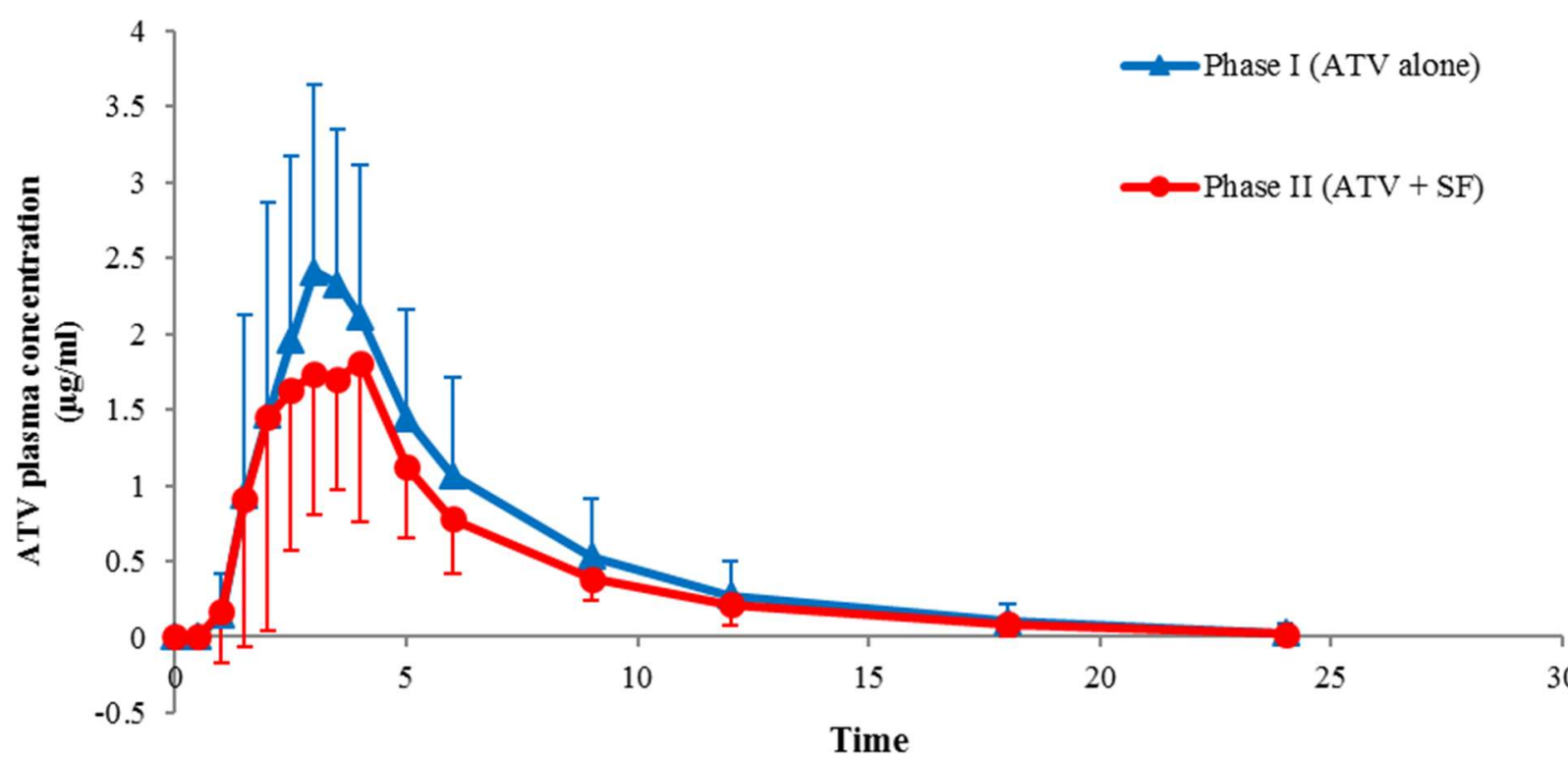

(Hours)

Figure 1. Comparison of mean ATV plasma concentration-time profiles for Phase I (ATV alone) and Phase II (ATV + $\mathrm{SF})$. Each point represents the mean \pm standard deviation $(\mathrm{n}=12)$ 


\section{Noncompartmental PK Analysis}

The PK parameters of ATV before and after coadministration with SF were determined by noncompartmental analyses. Exposure measures, $\mathrm{AUC}_{0-24}$ and $\mathrm{C}_{\max }$ were the primary PK parameters used to evaluate whether multiple dosing of SF altered the single-dose PK of ATV. Other parameters which were monitored included $t_{1 / 2}, t_{\max }$, and $k_{\mathrm{e}}$. These analyses were all conducted using the SAS ${ }^{\circledR}$ software (version 9.1.3, SAS Institute Inc, Cary, North Carolina, USA) and have been reported in the literature [19].

\section{Population Compartmental PK Analysis}

All concentration vs. time data were also simultaneously characterized and explained by a population compartmental model created with ADAPT5 ${ }^{\circledR}[26]$. Several models were created in order to explain appropriately and in a simultaneous manner all concentrations of ATV whether or not SF was administered. Models were modified in a sequential manner in order to obtain the most appropriate model to describe and explain all data. Quality of fit between potential models were compared using various different tools. A new preferred model compared to a previous model had to possess many or all of the following attributes: A lower Minimum value of the Objective Function (MOF) and of the Akaike Information criterion test (AIC), a better quality of fit as evidenced by improved predicted versus observed concentrations over time for ATV data in every subject, a lower value of the residual variability, and an improvement in other different graphical representations such as the weighted residuals versus predicted concentrations, and weighted residuals versus time.

Once a structural model was found to be the most appropriate and declared to be final, a population PK analysis was undertaken with this final model to ensure the robustness of the results. The population PK analysis was done using a mixed-effect modeling approach as implemented in the ITS tool of ADAPT5 ${ }^{\circledR}$ [26]. Validation of the population PK study results were conducted using visual predictive checks and nonparametric bootstraps. One thousand studies were simulated and the observed data from the study were to be overlaid on the graphical representation of the 5-95\% confidence intervals from the nonparametric bootstraps.

\section{RESULTS AND DISCUSSION}

The different PK models investigated to describe the concentration vs time data of ATV regardless of the absence or presence of SF are presented in Table 1. Inspection of the mean concentration-time profiles in Figure 1[19] suggested that the absorption of ATV appeared to have mixed mechanisms, in that a zeroorder "active" absorption process (depicted by the PK parameter $\mathrm{K}_{0}$ ) was occurring at the same time as a first order "passive" process (represented by the PK parameter $\mathrm{K}_{\mathrm{a}}$ ). The first model was therefore a one compartment model with a dual-absorption process, where the co-administration of SF could change all of the PK parameters of the model (e.g., $\mathrm{K}_{\mathrm{a}}, \mathrm{T}_{\mathrm{lag}}, \mathrm{K}_{0}$, $\mathrm{CL} / \mathrm{F}$ and $\mathrm{V} / \mathrm{F}$ ). The fit, as shown by high MOF, AIC and residual variability, suggested that the one compartment model was not appropriate, therefore the model was changed to a two-compartment one (Model \#2). This change resulted in a very good fit of the observed data with a low residual variability of $10 \%$, indicating that the model explained the data very well. This model took into account the potential of SF to affect the overall bioavailability (F) of ATV as well its CL and V, whether or not changes in $\mathrm{F}$ occurred. In addition, the model made provision for potential changes in all absorption parameters $\left(\mathrm{K}_{\mathrm{a}}\right.$, $\mathrm{T}_{\text {lag }}$ and $\mathrm{K}_{0}$ ), since these appeared necessary as evidenced by the concentration-time profiles of ATV and ATV + SF and the noncompartmental PK results. Results from this model suggested that once changes in F for ATV occurred, no additional changes in $\mathrm{V}$ and $\mathrm{CL}$ were observed, thus the next model allowed the changes to be only in CL/F and $\mathrm{V} / \mathrm{F}$ (Model \#3) of ATV without a separate F parameter, while Model \#4 allowed the change in $\mathrm{CL} / \mathrm{F}$ and $\mathrm{V} / \mathrm{F}$ of ATV, caused by SF to result only from a change in $F$. In this case, SF would not change the true systemic $\mathrm{V}$ or $\mathrm{CL}$ parameters of ATV, but only $F$, thereby resulting in a change in V/F and CL/F. Model \#4 gave an improved MOF and AIC and was therefore judged to be the most optimal model for the concentration-time data of ATV in the absence and presence of SF. Goodness of fit figures as well as the fitted versus observed concentrations of ATV with and without SF co-administration in one subject are presented in Figures 2 and 3, respectively. The model was validated using nonparametric bootstraps and visual predictive checks. These are presented in Figure 4, where it can be seen that the observed data were well characterized by the PK model. 
The population PK analysis conducted with model\#4 (Table 2) suggested that SF decreased ATV absorption by $13 \%$, via an "active" process $\left(\mathrm{K}_{0}\right)$. A $13 \%$ reduction in bioavailability indicates that the concomitant administration of SF does not cause a change in any other PK parameter of ATV, namely, distribution, elimination and "passive" absorption (Ka) of the PI. The hypothesis that SF reduces the bioavailability of ATV via absorption and not elimination is thus probable. Moreover, the role of transporters and/or CYP enzymes of the intestinal tissue in mediating the effect are also supported as only the "active" and not the "passive" absorption process of ATV was impacted after administration of SF. a)

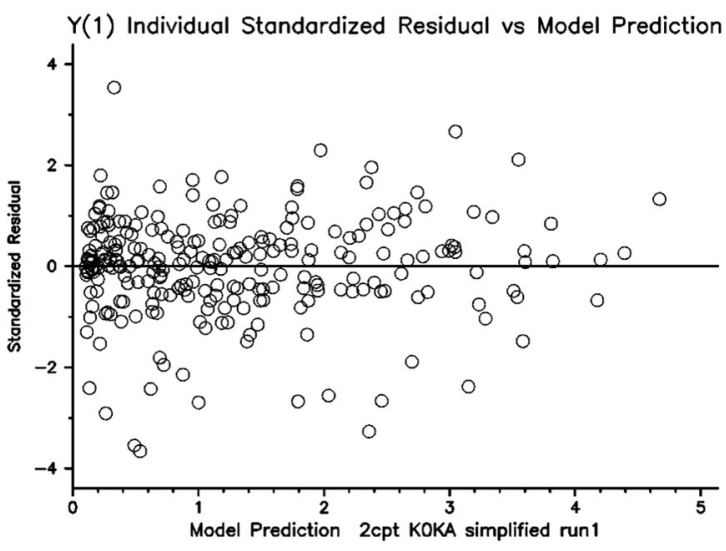

b)

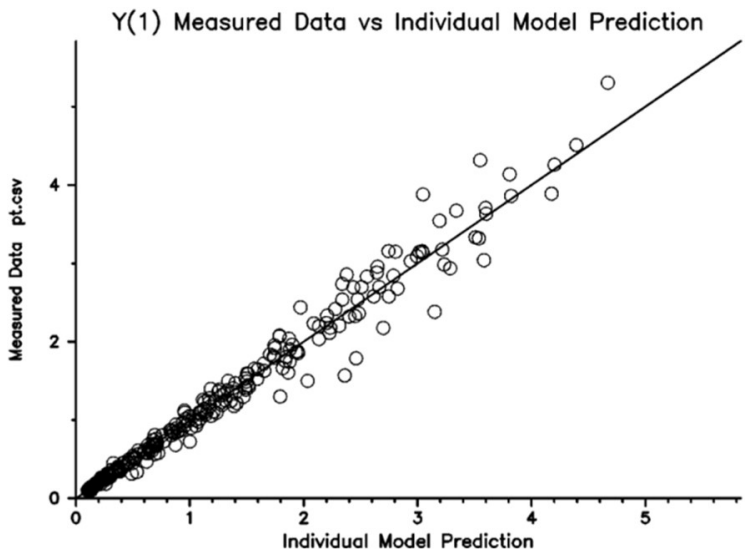

Figure 2. Goodness of fit representations for ATV plasma concentrations using the final Model \#4 (a) Individual Standardized Residual vs Model prediction and (b) Measured Data vs Individual Model Prediction.

a)

Fitted (-) and Observed (.) concentrations of Atazanavir

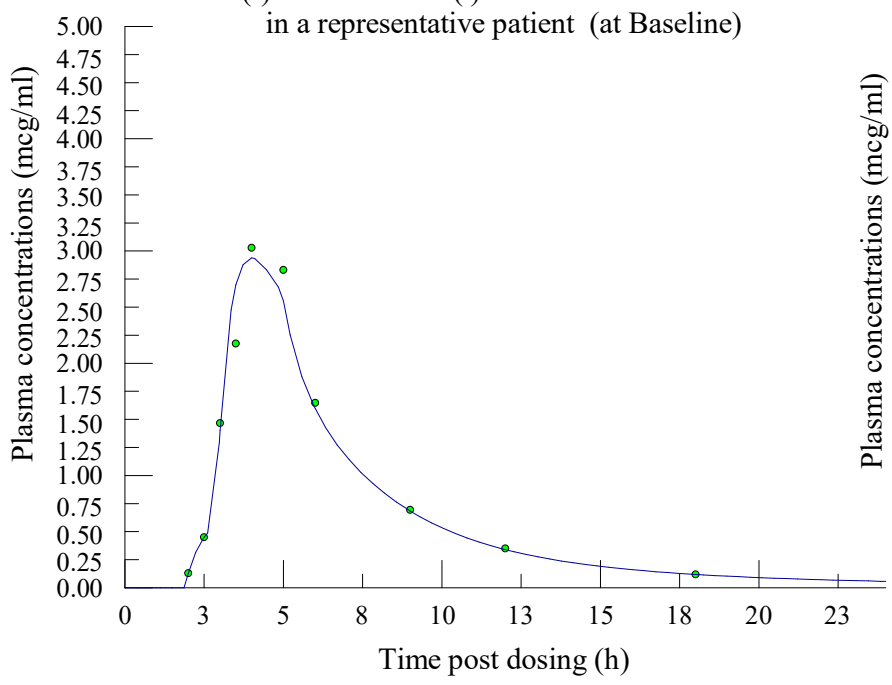

b)

Fitted (-) and Observed (.) concentrations of Atazanavir in a representative patient (After Sutherlandia Frutescens)

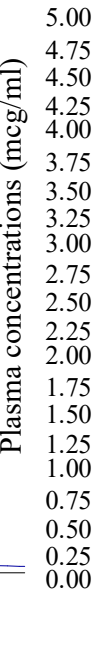

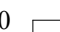

-

ATV at baseline (Day 1) and (b) ATV after 15 days administration of SF 

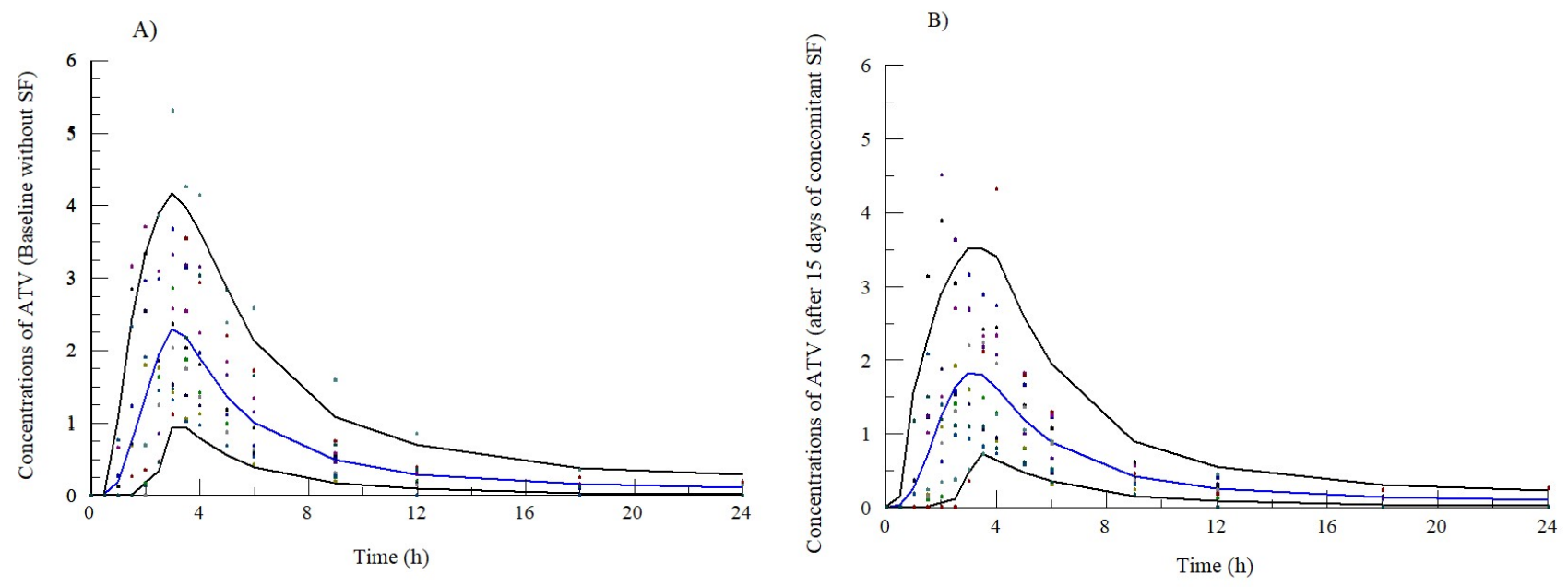

Figure 4. Visual Predictive Checks of the ATV PK model at baseline (Panel A) and after 15 days of co-administration of SF (Panel B)

Table 1: PK models investigated during the Population PK analysis in order to appropriately describe the ATV concentrations whether or not SF is co-administered (Retained final model is in bold)

\begin{tabular}{|c|c|c|c|c|c|}
\hline \multicolumn{3}{|c|}{ Model tested } & \multicolumn{3}{|c|}{ Quality of Fit } \\
\hline Model \# & ATV Alone & $\begin{array}{l}\text { Change in parameters } \\
\text { allowed when SF is co- } \\
\text { administered }\end{array}$ & $\begin{array}{c}\text { Residual } \\
\text { variability }\end{array}$ & MOF & AIC \\
\hline 1 & $\begin{array}{l}1 \text {-cpt model with } 1 \text { active } \\
\left(\mathrm{K}_{0}\right) \text { and } 1 \text { passive }\left(\mathrm{K}_{\mathrm{a}}\right) \\
\text { absorption process }\end{array}$ & $\begin{array}{l}\mathrm{K}_{\mathrm{a}}, \mathrm{Tl}_{\mathrm{ag}}, \mathrm{K}_{0}, \mathrm{CL} / \mathrm{F} \text { and } \mathrm{V} / \mathrm{F} \text { are } \\
\text { estimated separately with and } \\
\text { without SF }\end{array}$ & $26 \%$ & 102.964 & 286.964 \\
\hline 2 & $\begin{array}{l}\text { Changed to a 2-cpt with } \\
1 \text { active }\left(\mathrm{K}_{0}\right) \text { and } 1 \\
\text { passive }\left(\mathrm{K}_{\mathrm{a}}\right) \text { absorption } \\
\text { process }\end{array}$ & $\begin{array}{l}\mathrm{K}_{\mathrm{a}}, \mathrm{Tl}_{\mathrm{ag}}, \mathrm{K}_{0}, \mathrm{~F} \mathrm{CL} / \mathrm{F} \text { and } \mathrm{V} / \mathrm{F} \\
\text { are estimated separately with } \\
\text { and without SF }\end{array}$ & $10 \%$ & -351.112 & -77.1121 \\
\hline 3 & Same as Run\#2. & $\begin{array}{l}\mathrm{K}_{\mathrm{a}}, \mathrm{Tl}_{\mathrm{ag}}, \mathrm{K}_{0}, \mathrm{CL} / \mathrm{F} \text { and } \mathrm{V} / \mathrm{F} \text { are } \\
\text { estimated separately with and } \\
\text { without SF }\end{array}$ & $10 \%$ & -396.406 & -154.406 \\
\hline 4 & Same as Run\#2. & $\begin{array}{l}K_{\mathrm{a}}, T_{\text {lag }}, K_{0} \text { and } F_{\text {rel }} \text { are } \\
\text { estimated separately with } \\
\text { and without } S F\end{array}$ & $10 \%$ & -508.775 & -296.775 \\
\hline
\end{tabular}

\section{Abbreviations:}

1-cpt $=$ one-compartment model; 2 -cpt $=$ two-compartment model; $\mathrm{Ka}=$ absorption rate constant;

Tlag = lag time; $\mathrm{K}_{0}=$ zero order absorption rate constant; $\mathrm{CL}=$ clearance; $\mathrm{V}=$ volume of distribution;

$\mathrm{F}=$ bioavailability 
Table 2: Individual PK parameter results from the population PK analysis (Final Model \#4) describing potential changes in ATV that would be due to SF co-administration.

\begin{tabular}{|c|c|c|c|c|c|c|}
\hline & \multirow{2}{*}{ PK parameters } & \multicolumn{2}{|c|}{$\begin{array}{c}\text { Day } 1 \\
\text { (ATV alone) }\end{array}$} & \multicolumn{2}{|c|}{$\begin{array}{c}\text { Day } 8 \\
(\mathrm{ATV}+\mathrm{SF})\end{array}$} & \multirow{2}{*}{ Change from Day 1 to Day 8} \\
\hline & & Mean & CV \% & Mean & CV \% & \\
\hline \multirow{4}{*}{$\begin{array}{l}\text { Relative } \\
\text { Bioavailability } \\
\text { Absorption }\end{array}$} & Frel & & & $87 \%$ & $31.4 \%$ & \multirow{11}{*}{$\begin{array}{l}\text { SF appeared to decrease the } \\
\text { overall bioavailability of ATV } \\
\text { by } 13 \% \text { (Frel). Most of this } \\
\text { change appeared to be caused } \\
\text { by a change in the \% of dose } \\
\text { absorbed via a zero-order } \\
\left.\text { active process (K }{ }_{0}\right) \text { which } \\
\text { decreased by } 13 \% \text {. } \\
\text { Change only due to an overall } \\
\text { bioavailability change (F) by } \\
\text { SF and not due to any change } \\
\text { in systemic clearances or } \\
\text { volumes of distribution. }\end{array}$} \\
\hline & $\begin{array}{l}\text { Percentage of } \\
\text { absorption through } \\
K_{0} \text { route }\end{array}$ & $20.68 \%$ & $68 \%$ & $7.8 \%$ & $53 \%$ & \\
\hline & $\begin{array}{l}\mathbf{T}_{\text {lag }} \text { before } \mathbf{K}_{\mathbf{a}} \\
\text { starts }\end{array}$ & 2.08 & $25 \%$ & 1.70 & $51 \%$ & \\
\hline & $\mathbf{K}_{\mathbf{a}}$ & 0.35 & $26 \%$ & 0.37 & $40 \%$ & \\
\hline \multirow{4}{*}{$\begin{array}{l}\text { Distribution } \\
\text { and Clearance } \\
\text { parameters }\end{array}$} & $V_{c} / F(L)$ & 18.8 & $65 \%$ & \multirow{4}{*}{\multicolumn{2}{|c|}{$\begin{array}{l}\text { Note: Day } 1 \text { values } \\
\text { divided by } F_{\text {rel }}\end{array}$}} & \\
\hline & $\mathbf{V}_{\mathrm{p}} / \mathbf{F}(\mathbf{L})$ & 449 & $145 \%$ & & & \\
\hline & CL/F (L/h) & 26.8 & $43 \%$ & & & \\
\hline & $\mathbf{C L d} / \mathbf{F}$ & 16.7 & $72 \%$ & & & \\
\hline \multirow[t]{3}{*}{ Half -lives } & $\begin{array}{l}\text { Absorption half- } \\
\text { life }\left(\mathbf{K}_{\mathbf{a}}\right)\end{array}$ & $2.1 \mathrm{~h}$ & $28 \%$ & $2.2 \mathrm{~h}$ & $47 \%$ & \\
\hline & $\begin{array}{l}\text { Distribution half- } \\
\text { life }\end{array}$ & $0.3 \mathrm{~h}$ & $63 \%$ & No change & & \\
\hline & $\begin{array}{l}\text { Elimination half- } \\
\text { life }\end{array}$ & $\begin{array}{l}14.8 \mathrm{~h} \\
\text { (arithmetic } \\
\text { mean) }\end{array}$ & $149 \%$ & & & \\
\hline
\end{tabular}

\section{Abbreviations:}

1-cpt $=$ one-compartment model; 2-cpt $=$ two-compartment model; $\mathrm{Ka}=$ absorption rate constant;

Tlag = lag time; $\mathrm{K} 0=$ zero order absorption rate constant; $\mathrm{CL}=$ clearance; $\mathrm{V}=$ volume of distribution;

$\mathrm{F}=$ bioavailability

\section{CONCLUSIONS}

The population PK Compartmental Analysis of ATV before and after a two-week regimen of Phyto Nova Sutherlandia SU1 tablets which contain SF plant material indicated that a two compartment model with a dual absorption mechanism best explained the data. The dual absorption mechanism is hypothesized to reflect "passive" (first-order, $\mathrm{K}_{\mathrm{a}}$ parameter) and "active" (zero-order, $\mathrm{K}_{0}$ parameter) absorption processes. The population PK analyses suggested that the mechanism by which SF reduced the overall bioavailability of ATV may be modulated via the inhibition of the "active" absorption process. This study has highlighted the utility of population PK analyses in postulating the most probable mechanism(s) whereby an ATM or a herbal medicine interacts with an allopathic drug. This may be particularly useful when in vitro studies show contradictory results for different extracts and components of the ATM or herbal medicine.

\section{REFERENCES}

1. Babb DA, Pemba L, Seatlanyane P, Charalambous S, Churchyard GJ, Grant AD. Use of traditional medicine in the era of antiretroviral therapy: experience from South Africa. 15th International Conference on AIDS 2004; Bangkok, Thailand abstract no. B10640. http://gateway.nlm.nih.gov/MeetingAbstracts/ma?f= 102276492.html;

2. Langlois-Klassen D, Kipp W, Jhangri GS, Rubaale T. Use of traditional herbal medicine by AIDS patients in Kabarole district, western Uganda. Am J Trop Med Hyg, 2007; 77: 757-763.

3. Malangu N. Self-reported use of traditional, complementary and over-the-counter medicines by HIV-infected patients on antiretroviral therapy in Pretoria, South Africa. Afr J Tradit Complement Altern Med 2007; 4: 273-278.

4. Peltzer K, du Preez NFD, Ramlagan S, Fomundam H. Use of traditional complementary and alternative medicine for HIV patients in KwaZulu-Natal, South Africa. BMC Publ Health, 2008; 8: 255. 
5. Watson RR, Stanaway, JD. African medicinal plants for the treatment of HIV/AIDS, in: Medicine in Clinical Practice, 2008; 13-30, GAB International.

6. Bousquet L, Roucairol C, Hembury A, Nevers MC, Creminon C, Farinotti R, Mabondzo, A. Comparison of $\mathrm{ABC}$ transporter modulation by atazanavir in lymphocytes and human brain endothelial cells: $\mathrm{ABC}$ transporters are involved in the atazanavir-limited passage across an in vitro human model of the bloodbrain barrier. AIDS Research and Human Retroviruses, 2008; 24: 1147-1154.

7. Janneh O, Anwar T, Jungbauer C, Kopp S, Khoo SH, Back DJ, Chiba P. P-glycoprotein, multidrug resistance-associated proteins and human organic anion transporting polypeptide influence the intracellular accumulation of atazanavir. Antiviral Therapy, 2009; 14: 965-974.

8. Le Tiec C, Barrail A, Goujard U, Taburet AM, Clinical pharmacokinetics and summary of efficacy and tolerability of atazanavir. Clinical Pharmacokinetics, 2005; 44: 1035-1050.

9. Müller AC, Patnala S, Kis O, Bendayan R, Kanfer I. Interactions between phytochemical components of Sutherlandia frutescens and the antiretroviral, atazanavir in vitro: implications for absorption and metabolism. Journal of Pharmacy and Pharmaceutical Sciences, 2012; 15: 221- 233.

10. van Wyk BE, Albrecht C. A review of the taxonomy, ethnobotany, chemistry and pharmacology of Sutherlandia frutescens (Fabaceae). Journal of Ethnopharmacology, 2008; 119: 620-629.

11. Fu X, Li XC, Smillie TJ, Carvalho P, Mabusela W, Syce J, Johnson Q, Folk W, Avery MA, Khan IA. Cycloartane glycosides from Sutherlandia frutescens. Journal of Natural Products, 2008; 71: 1749-1753.

12. Fu X, Li XC, Wang YB, Avula B, Smillie TJ, Mabusela, W, Syce J, Johnson Q, Folk W. Khan IA. Flavonol glycosides from the South African medicinal plant Sutherlandia frutescens, Planta Medica, 2010; 76: 178-181.

13. Avula B, Wang YH, Smillie TJ, Fu X, Li XC, Mabusela W, Syce J, Johnson Q, Folk W, . Khan IA. Quantitative determination of flavonoids and cycloartanol glycosides from aerial parts of Sutherlandia frutescens (L.) R. BR. by using LCUV/ELSD methods and confirmation by using LCMS method, Journal of Pharmaceutical and Biomedical Analysis, 2010; 52: 173-180.

14. Committee for Proprietary Medicinal Products, Note for Guidance on the Investigation of Drug Interactions, European Medicines Agency, London, 1997.

15. US Food and Drug Administration, Guidance for industry: In vivo drug metabolism/drug interaction studies-study design, data analysis, and recommendations for dosing and labeling. 1999.
16. Strnad, C F, Therapeutics Products Programme Guidance Document, Drug-drug interactions: Studies In Vitro and In Vivo, Health Canada, 2000.

17. US Department of Health and Human Services, Guidance for Industry: Statistical Approaches to Establishing Bioequivalence. Food and Drug Administration, Rockville, MD, 2001.

18. Zhang P. A simple formula for sample size calculation in equivalence Studies. Journal of Biopharmaceutical Statistics, 2003; 13: 529.

19. Müller, A.C, Skinner, M.F. and Kanfer, I. Effect of the African Traditional Medicine, Sutherlandia frutescens, on the bioavailability of the antiretroviral protease inhibitor, atazanavir. Evidence-based Complementary and Alternative Medicine, 2013; 4: 324618.

20. Colucci P, Pottage JC, Robison H, Turgeon J, Ducharme MP. Effect of a single dose of ritonavir on the pharmacokinetic behavior of elvucitabine, a nucleoside reverse transcriptase inhibitor, administered in heathy volunteers. Antimicrob Agents Chemother 2009; 53(2):646-50.

21. Colucci P, Pottage JC, Robison H, Turgeon J, Schurmann D, Hoepelman IM, Ducharme MP. Antimicrob Agents Chemother 2009; 53(2):662-9.

22. Bonate PL, Ahamadi M, Budha N, et al. Methods and strategies for assessing uncontrolled drug-drug interactions in population pharmacokinetic analyses: results from the International Society of Pharmacometrics (ISOP) Working Group. J Pharmacokinet Pharmacodyn 2016;43:123-135.

23. Müller AC, Kanfer I. An efficient HPLC method for the quantitative determination of atazanavir in human plasma suitable for bioequivalence and pharmacokinetic studies in healthy human subjects. Journal of Pharmaceutical and Biomedical Analysis, 2010; 53, 113-118.

24. D'Argenio DZ, Schumitzky A, Wang X. ADAPT 5 User's guide: Pharmacokinetic/Pharmacodynamic systems analysis software. Biomedical Simulations Resource, Los Angeles, 2009. 